\title{
Using legimation code theory to track pedagogic practice in a South African English home language poetry lesson
}

\section{Fiona Jackson}

\begin{abstract}
This paper utilises two dimensions of Legitimation Code Theory, Specialisation and Semantics, to describe and analyse aspects of the poetry pedagogy of a South African home language subject English teacher. The Specialisation analysis illuminates how, while the lesson is oriented towards social relations in its focus on cultivating learners' literary gaze, the teacher's pedagogy exhibits varying emphases on epistemic relations and social relations in different phases of the lesson. These concepts facilitate more precise description of the pedagogy, which assists in clarifying and explicating the nature of the pedagogy of a teacher working with a cultural heritage orientation to literary instruction. Analysis within the Semantic dimension enables the tracking of pulses of shifts in abstraction and particularity through the lesson. This highlights the ways in which the teacher moves between more and less abstract and concrete forms of knowledge, which implicitly models ideational networks required for higher levels of close textual analysis.
\end{abstract}

The Lesson

Edward Lucie-Smith

"Your father's gone," my bald headmaster said.

His shiny dome and brown tobacco jar

Splintered at once in tears. It wasn't grief.

I cried for knowledge which was bitterer

Than any grief. For there and then I knew

That grief has uses - that a father dead

Could bind the bully's fist a week or two;

And then I cried for shame, then for relief.

I was a month past ten when I learnt this:

I still remember how the noise was stilled

in school-assembly when my grief came in.

Some goldfish in a bowl quietly sculled

Around their shining prison on its shelf.

They were indifferent. All the other eyes

Were turned towards me. Somewhere in myself

Pride, like a goldfish, flashed a sudden fin. 


\section{Introduction}

Subject English is a protean beast - multiply defined and highly contested (Macken-Horarik, 2014, 2013, Gibbons, 2009, Green, 2008, Christie and Macken-Horarik, 2007). Given the variety of disciplinary sources from which it draws (humanities to social sciences), subject English presents a particularly intricate knowledge base. Within many school systems it serves as both the medium for knowledge building and communication and the object of study itself (Larsen-Freeman and Freeman, 2008). The complex role it thus performs in such contexts, in providing the communicative means for learners to access wider and increasingly abstracted, formalised systems of knowledge, points to the importance of developing more rigorous, cumulative understanding of the nature of the knowledge practices enacted within subject English classrooms. The insights to be generated from application of Legitimation Code Theory concepts potentially provide access to deep level organising principles useful to the field of English education, and education more widely. Teachers and learners often struggle with the 'invisible' nature of what constitutes mastery in literary studies. The explication of knowledge practices within English literary processes can contribute to increased consciousness amongst teachers of the range of pedagogic formations available to them, and the implications of these for their practice and their learners' progress. In this article I focus particularly on processes of unpacking the knowledge practices of subject English poetry instruction.

\section{The context of subject English education}

Within the South African school system subject English occupies an uneasy space. Historically and ideologically associated with imperial British colonial rule, English yet holds considerable contemporary value for many South Africans as a local and globalised lingua franca offering access to economic capital and advancement (Wright, 2002). Drawing content from a wide set of disciplinary sources, varying temporally and locationally in their influence, the goals and content base of English-as-Subject can vary greatly (Clark, 2005). These can range from knowledge about language and literature, to acting in, and responding to life, using language (Kantor, 2001). Curriculum goals for school English range from basic literacy skills through personal growth approaches to literary and critical literacy studies (Macken-Horarik, 
2014, Sperling and DiPardo, 2008, Christie and Macken-Horarik, 2007, Morrell, 2005, Pike, 2003, Marshall, 2003, Harley, 1991).

Subject English teachers consequently work with wide ranging choices for content and process. Unsurprisingly, research reveals English teachers' pedagogic identities as mobile yet contingent on their contexts and deep epistemologies regarding language, literacy, and learning. Competing forces and values can thus co-exist within teachers' beliefs and practices (Gibbons, 2009, Slonimsky and Brodie, 2006, Xinmin and Adamson, 2003). The task of capturing and understanding the pedagogy of English teachers thus requires attention to multi-faceted dimensions and levels.

Extant research mostly comprises small case studies using either inductively derived categories of analysis or pedagogically normative lenses, often investigating issues within binary categorisations such as communicative versus traditional, or learner- versus teacher- centred (Shaalukeni, 2000 in Weideman, Tesfamariam and Shaalukeni, 2003, Xinmin and Adamson, 2003, Slonimsky and Brodie, 2006). International case studies have investigated philosophies and subject knowledge of English teachers, via interviews (Marshall, 2000, Ellis, 2009). Local case studies have inductively explored English teacher responses to curriculum change and difficulties in engaging learners in literature study (Carminati, 2007, Dyer, 2007). There remains a dearth of research, particularly locally, of pedagogically well theorised descriptions of the practices of English teachers, focusing on the nature of the knowledge base of these practices.

This paper explores the contribution that Legitimation Code Theory (LCT) brings to the task of unpacking how teachers cultivate a literary gaze through their practice. Firstly, I briefly outline the broad project of LCT, and introduce two of its dimensions, Specialisation and Semantics. Thereafter I demonstrate the insights to be gained from a multi-dimensional depth analysis of key moments in one lesson of a KwaZulu-Natal English Home Language teacher, as she teaches Edward Lucie-Smith's poem, The Lesson, to her twenty-one Grade 10 learners. 


\section{Theoretical contextualisation}

Ensor and Hoadley (2004) argue the need for South African classroom based research rooted in pedagogic theory and focusing upon the messages conveyed through the form of disciplinary instruction. Without such theory, much analysis of classroom practice works with assumed normative views of pedagogic best practice lacking "in-depth description of any particular aspect of classroom activities" (p.86). They index the need for non-evaluative, theorised analytic schemes, enabling more precise rendering of types of pedagogy. LCT offers a theoretically rigorous, supple lens that can spotlight pedagogic issues from both epistemological and relational perspectives. Rooted in social realism, LCT addresses issues of social practice, working to articulate the underlying organisational principles of social fields. LCT aims to build a sociology of knowledge, addressing the gap of 'knowledge blindness (Maton, 2014) in educational research. Knowledge is understood as something real, with different types of knowledge varying in structure, properties and effects. LCT seeks deeper understanding of how knowledge structures impact upon fields, and of forms of knowledge as a medium of the educational message. That is, it investigates how knowledge practices themselves are structured. Describing the principles and legitimation codes controlling educational arenas is a vital first step to explaining educational practices.

Social practices are underpinned by legitimation codes. These operate as claims for the legitimacy of people's actions, or, "for the organising principles embodied by their actions" (Maton, 2014, p.24). Legitimation codes comprise structuring principles with consequences as their inherent structures vary with differing effects. Additionally, their form moulds the potential of what can be communicated. The concept facilitates focus on both the sociological nature of knowledge practices and the epistemological nature of potentially legitimate knowledge claims and thus both on analyses of 'relations to' knowledge practices and analyses of 'relations within' knowledge practices.

LCT provides a multidimensional set of concepts for the analysis of actors' social practices and dispositions. I shall focus here on two: firstly, Specialisation and subsequently, Semantics. Within the educational arena specialisation codes are made up of knowledge practices embodying both epistemic relations (ER) and social relations (SR). Epistemic relations refer to relations between practices and their objects while social relations refer to 
relations between practices and their subjects or originators. These concepts build on Bernstein's notions of classification and framing (1996). Classification refers to the strength of boundary maintenance between contexts or categories. Framing refers to the location of control inside contexts or categories. Stronger framing points to greater control from above. Therefore, stronger epistemic relations refer to practices which place firm boundaries and control around what can legitimately constitute objects of study and what procedures may be used. Stronger social relations refer to the placement of strong boundaries and control around who may be recognised as legitimate knowers (Maton, 2014). Tracking the details of specialisation codes necessitates identifying whether epistemic relations or social relations are more emphasised.

Maton further argues the need to move beyond dichotomising typologies in educational research, and so visualises epistemic relations and social relations as intersecting continua that generate a Cartesian plane. This produces a topological space comprising four specialisation codes - knowledge, élite, knower, relativist, as set out in Figure 1 below:

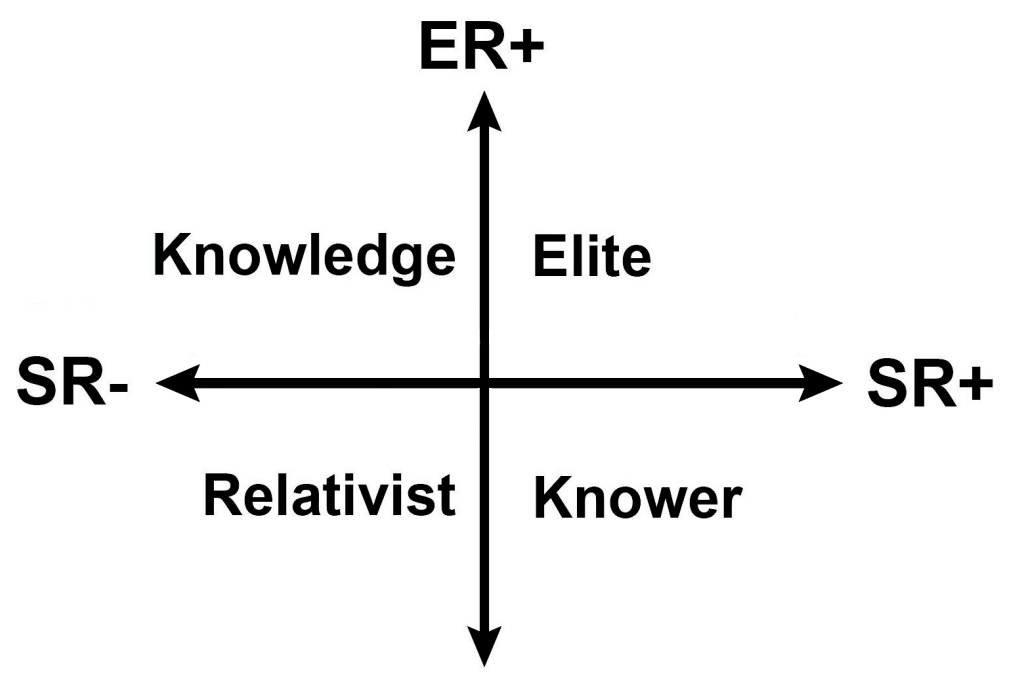

ER-

Figure 1: Specialization codes (adapted from Maton, 2014, p.30) 
This topological space provides possibilities for separate variations in the strength of epistemic relations and social relations. The mapping of infinite numbers of positions along continua of relative strengths is thus possible, along with tracing shifts of position within quadrants.

Knowledge codes are those which strongly mark off what counts as legitimate objects and/or methods of study. The personal attributes of those who do the studying is less emphasised. This is schematised as ER+, SR-. Physics is an example of a code where specialised knowledge of particular objects of study, using strongly controlled procedures, is stressed. In principle, anyone may participate in doing physics, as long as they master the accepted procedures for knowledge building.

In contrast, knower codes ground assertions of legitimacy in particular kinds of knowers. There is stronger classification and framing of social relations, with who makes claims being the most important factor. Differences between knowers are stressed. Wide ranging knowledge assertions, methods and procedures are largely a matter of individual choice. Maton identifies different types of knowers, including social and cultivated. Social knower codes are based on social distinctions such as class, gender and ethnicity and aim to speak the experiences of knowers, with truth being established via the 'voice' (Maton, 2014). Cultivated knower codes result from long immersion in a particular way of knowing, generating a cultivated disposition. School subject English will most typically fall into the ER-, SR+, or knower code quadrant, where social relations predominate in relation to the importance of knowers' responses to language and literary texts (usually through the cultivation of the dispositions of knowers into a range of possible gazes). The topological 'space' thus facilitates fine-grained analyses plotting nuanced variations in such gazes. It can move descriptions of pedagogic practice beyond static tabulations, to accounting for variations within individual teacher's practices and between different teachers and contexts.

The other dimension of LCT deployed here is that of Semantics. This facilitates focus on what constitutes, and promotes, cumulative theorising and learning, as opposed to segmented thinking. Maton asks how educational knowledge can facilitate greater conceptual, integrative hierarchisation, as opposed to segmented learning. He argues that segmentalism [comprising] "a series of discrete ideas or skills, rather than cumulatively building on previously encountered knowledge" (2014, p.107), can limit learners' capacities to abstract and transfer knowledge. Cumulative learning facilitates 
transfer of knowledge between contexts and through time, while segmented learning often restricts transfer, leaving learners with knowledge locked within the 'semantic gravity well' of particular contexts. Maton proposes the notions of cumulative learning, semantic gravity and semantic density as key tools to articulate the underlying organising principles enabling understanding of knowledge building processes.

Semantic gravity refers to the degree to which the meaning of practices relates to their contexts. Maton elaborates:
This semantic gravity may be relatively stronger or weaker along a continuum. When semantic gravity is stronger, meaning is more closely related to its social or symbolic context of acquisition or use; when it is weaker, meaning is less dependent on its context. One can also describe processes of strengthening semantic gravity, such as moving from abstract or generalized ideas towards concrete and delimited cases, and weakening semantic gravity; such as moving from the concrete particulars of a specific case towards generalizations and abstractions whose meanings are less dependent on that context (2014, p.110).

Broadly, then, semantic gravity equates to degrees of abstraction and concretisation. In close juxtaposition with semantic gravity, Maton proposes the notion of semantic density which
refers to the degree of condensation of meaning within socio-cultural practices (symbols, terms, concepts, phrases. . .). . . The stronger the semantic density ( $\mathrm{SD}+$ ), the more meanings are condensed within practices; the weaker the semantic density (SD-) the less meanings are condensed. The strength of semantic density of a practice or symbol relates to the semantic structure in which it is located (p.129).

So, within the study of English poetry, the term 'iambic pentameter' is characterised by relatively strong semantic density, condensing information about the stress pattern of English syllables, the pairing of stressed and unstressed syllables in 'feet' and the sequencing of these pairs in groups of five feet. 'Iambic pentameter' is also connected to networked knowledge systems of terms about rhythm and meter in poetry.

Maton again presents the principles of semantic gravity and semantic density as continua, enabling fine plotting of infinite variations in strengths of realisation of each principle through pedagogic processes and products. Combining semantic density and semantic gravity as analytic tools permits the tracking of shifts in the nature and coherence of pedagogic discourse over time, using notions of semantic waves, and degrees of semantic flow which 
can be visualised as semantic profiles (Matruglio, Maton and Martin, 2013). However it is important to remain aware that each principle can vary in strength (and be plotted) independently over time.

\section{Contextualisation of the analysed lesson}

This lesson occurred in a formerly all-white, fee levying, state school currently serving dominantly middle-class communities. ${ }^{1}$ Of the 21 learners, most were African boys, with 3 Indian boys and 7 African girls. This meant that an English Home Language curriculum was being taught to a class with a majority of English Additional Language speakers. The teacher, Mrs Aldridge (a pseudonym) is a white, middle-aged female, with over 15 years teaching experience.

In the next section I firstly present a schematic overview of the lesson, then demonstrate how a Specialisation analysis illuminates the forms of legitimation this teacher deploys in her pedagogic process. Thereafter I explore movements in strengths of semantic gravity and semantic density and how these contribute to the building of a particular literary gaze.

\section{Tracking specialisation in one instance of poetry pedagogy}

The focus of this fifty minute lesson is the development of the learners' literary gaze, in terms of practical criticism competencies. The teacher's overall goal is to elicit learner answers to the question 'What was the lesson learned by the poem's protagonist?' The class comprises six phases, summarised below, ${ }^{2}$ with the bulk of the time spent on phases four and five:

1 In 2008, when this lesson was observed and video recorded, the school of 1200 learners was racially integrated, with roughly equal proportions of white, African, Indian and mixed-race learners. This class had no white learners. Informed ethical consent was secured from the Education Department, the school and the teacher.

2 The full transcript of this lesson is available at https:ukzn.academia.edu/FionaJackson 
1. Settling in

2. Task Orientation:

The teacher identifies the lesson as literature, focusing on poetry.

3. Academic administration:

The teacher instructs learners on the required submission of a prior task

4. a) Task Orientation:

The teacher initiates a brainstorming exercise in response to the word 'lesson'

b) Plenary:

Teacher led discussion on connotations of 'lesson' and 'life lesson' (about 10 minutes)

5. a) Reading poem:

Learners read the poem in small groups and discuss the life lesson learned by the protagonist (about 15 minutes)

b) Plenary sharing:

The teacher leads whole group exploration of the difficulties of interpretation and what textual evidence provides support for inferences about the poem (about 12 minutes)

c) Learner completion of written questions on poem (about 5 minutes)

6. Conclusion:

The teacher makes concluding statements about the lesson.

The tightly structured process moves learners from a pre-reading task into close engagement with the poem's meaning. The poem can be located within a knower code, that is, an ER-, SR+ coding, expressing something of the poet's unique disposition and voice. However, in the pedagogic arena, the bases for approaching and relating to the text can vary, shifting along both the epistemic relations and social relations continua. At this point, Maton's distinction between the focus and basis of pedagogic practice is useful. Epistemic relations and social relations can be used to delineate the focus of knowledge claims, that is, the content of languages of legitimation. While the focus of this lesson can be argued to be oriented to social relations, through 
the cultivation of a particular kind of literary knower, there are variations in the strengths of legitimation codes forming the basis of the pedagogic practice. That is, legitimation codes outline the form of languages of legitimation (2014, p.31). When a poem is approached dominantly as an object containing information to be accurately retrieved and displayed, the specialisation basis tends towards stronger epistemic relations. However, approaching a poem, for example, as a personalised, affective meaning making experience for readers, leads towards a stronger basis of social relations.

A Specialisation analysis reveals different specialisation code emphases in the teacher's pedagogy within the overarching project of building the learners' literary gaze. It enables a more precise description of the pedagogy, which assists in clarifying and explicating the approach of literary instruction utilised. While the teacher initially foregrounds learners' experiences of 'lessons' and 'life lessons' (experiential brainstorming tasks consistent with a personal growth model of English instruction) to engage and activate in them her preferred frame of reference, thereby strengthening social relations, she subsequently focuses exclusively on the poem itself, independently of the poet, his life context and the life contexts of the learners. The brainstorming is not a prologue to learners exploring links between the poem and potentially similar situations in their own lives. It serves to make visible the most likely schemas to be activated in response to the title "The Lesson". The teacher then directs the learners to 'bracket' these schemas and reorients them to the idea of life lessons. Her main focus is on identifying the core meaning of the poem via close textual analysis of its details. Thus, while the overall focus of the lesson is on socialising the learners into a literary gaze, the basis of the lesson displays aspects characterised by stronger epistemic relations. This is evident through the teacher constructing the poem as an independent artefact and requiring learners to supply accurate textual information. That is, despite obliquely suggesting connections to real world experience, Mrs Aldridge engages the poem as a form of semantico-logical puzzle needing accurate decoding.

Early tasks such as the revision of the concepts 'denotation' and 'connotation' (from a prior lesson) are characterised by stronger epistemic relations These also feature at critical junctures in the teacher's later efforts to ensure accurate decoding of key textual details. The teacher constructs such details as the crucial base for establishing the poem's meaning. An early example of the class's engagement with the poem is initiated by the teacher's questions: 
"What would you say the catalyst is, um, for the speaker in the poem of this lesson? What has happened to him? Um, you know he has learned a lesson from something that has happened to him. What do you see has happened to him?"

Mrs Aldridge is asking for accurate identification of an event implied by the poem. In her ensuing exchanges with the learners, she accepts, validates and extends learners' responses and models elements of a cultivated literary gaze. Thus, in response to a learner responding 'his father has passed away', she focuses on the supporting textual evidence:

"Have a look at the first line 'your father's gone my bald headmaster said'. Presumably he's in a school context and he was called in by the headmaster to say 'your father's passed away."

The teacher signals the importance of clearly linking interpretive inferences with salient aspects of the text. This suggests brief strengthening of epistemic relations as partial highlighting of what kinds of inference and surmising are legitimate.

Once the learners are working in small groups considering what lesson the poem's protagonist learned, epistemic relations are strengthened, with the teacher reminding learners of the behaviours and strategies required. She directs learners to: "Talk about this because it means that you've got to explore the whole poem to work out what the lesson is" and to make notes. Such comments explicate some discursive criteria that learners must internalise. She also strengthens epistemic relations in her process of heading off problematic misreading, reformulating instructions with procedural and conceptual additions:

"No, no. . . it's the headmaster who has the bald head and the tobacco jar. . . the poem isn't concerned with what happened to the father because that is just the catalyst for $<$ ??? $>$ in his life $<$ ???> . The focus must be on what he learns - perhaps about himself from his father's passing. So don't allow your selves to go off on a tangent and look at possible causes of the death."

Here epistemic relations are stressed in the sense of implying "this piece of content in the poem does NOT equal ' $\mathrm{x}$ '." In exhorting learners not to "go off 
on a tangent" she signals boundaries for how to approach the poem, prioritising what the poem itself sets up: "the poem isn't concerned with what happened to the father. ." This focus on accurate knowledge of the content of the poem is subsequently reinforced as Mrs Aldridge realises many learners are pursuing the tangent. Consequently, addressing the entire class, she indicates how interpretation is limited by accurate reading of the contents of the poem:

“...I've just got to interrupt something and clarify something really important. The father has not died from smoking - can we eradicate that altogether. Um, the poet is not really, the speaker is not really concerned about the causes of death of the father - ah, what you should be focusing on, ah, is perhaps how his father's death has affected him and what he learns about himself. .. A brown tobacco jar is mentioned but that I would presume is the bald headmaster's. ... When he goes to the office he sees - shh he sees the headmaster has a shiny dome, which means no hair, and there's a brown tobacco jar next to headmaster, okay. So don't go off on a tangent now."

These comments suggest the importance of accurate understanding of the relationships between the details of the text, such as the jar, the headmaster, the father's death and the protagonist's thoughts in response to it. Sound understanding of such relationships is the critical springboard to the macro meaning of the life lesson. Her interventions again strengthen epistemic relations in stressing the importance of accurate reading of the text as a key element of her cultivated gaze: correct reading of the micro-details of a text followed by identification of plausible links amongst details before finally reading between the lines of such details.

Further strengthening of epistemic relations occurs after the teacher asks: "What does the speaker feel he should be thinking about?" Learner responses strengthen social relations, relieving the pressure of the hard work in establishing the required meaning, e.g., "Freedom!" The teacher's response also strengthens social relations, with low-key, wry acknowledgment of the comment: "Right, that was very unexpected." Responding to further learner offerings she says:

"Ja, you might have to support the family. But based on what this poem is saying, we don't know anything. All we know is that he 
lost the father. But we don't know anything about the speaker's the circumstance. So, um, we can't really read into something that is not directly in the text. All we know is that he's lost his fatherwe don't know about the circumstances."

Here Mrs Aldridge strengthens epistemic relations, presenting some of her limits of inferential possibility, excluding as illegitimate interpretations that cannot be linked to specific textual details. She reinforces these criteria by reiterating what is knowable from the poem (the father gone) and reformulates her questions specifically around this: "What does he feel he should be thinking about that?" This narrowing of the question clarifies her focus for the learners. When a learner says "his father" the teacher finally validates strongly:

"Absolutely - he should be mourning his father, he should be presumably thinking - and, and this is why he feels selfish."

In the ensuing discussion of whether a ten-year-old should be judged 'selfish' for thinking about the immediate benefit his father's death brings, the teacher strengthens social relations. Her most specific contribution, which she flags as very personal, comes in response to the line: "I still remember how the noise was stilled in school assembly when my grief came in". After eliciting and validating some learner interpretations of the line, she says:

"I tell you what very personally this phrase made me think of. We usually think of 'when your ship comes in', you know, when your luck comes in. And I thought about it in that context - that his grief, in a sense, has liberated him from the bullies that continually plague him."

Despite her identification of her comment as personal, what she shares is the associative link she makes between the poet's phrase and a conventionalised phrase (if seldom used in current South African English) - "When your ship comes in." This sharpens the view of her literary gaze as tending towards the detached, the cognitively associative and the epistemic. 'Very personally', for her, is a mental link, not an emotional or experiential connection.

Focusing on where epistemic relations are strengthened thus highlights the teacher's orientation to literary analysis as a cognitively motivated act, where continual attention to the ideational network of links between the macro 
meaning and the micro-details of the poem are the foundation for legitimate interpretive acts. These relatively stronger epistemic relations are interludes within a lesson characterised mostly by stronger social relations, since the overall thrust is to produce learner-subjects who can identify, experience, and internalise the message of the poem as refined meaning. Social relations are strengthened where the focus is on:

(a) building desired frames of reference in the learners,

(b) creating a bridge between learners' existing experience and the 'world' of the poem,

(c) regulative control of learners,

(d) relieving the pressure of establishing the desired interpretations amongst the learners, and

(e) fostering learners' interpretive activities.

The early brainstorming task, where learners have to "come up with about three or four connotations or personal associations that [lessons] has for you", foregrounds learners' personal experiences. In leading the plenary the teacher strengthens social relations in defending a learner's association: "it's an amount of things". Challenging learners' laughter, the teacher asserts:

"Nobody must laugh at someone's personal connotation. . . . No one can say your connotation is wrong or right."

This indexes an element of the teacher's grounds for a personal gaze associations based on individual experiences. Implicitly, this pre-emptively contrasts with the teacher's later comments on the trickiness of interpreting poems.

In shifting focus from connotations of 'lesson' to examples of 'life lessons' the teacher is building a specific, preparatory frame of reference in the learners. Though she has a clear epistemic goal - ensuring learners do not presume 'The Lesson' to be a formal school lesson, the basis of her process of elicitation emphasises stronger social relations. Her responses range from seeking clarification from learners to simply acknowledging the pain of the experience reported. For example, as in:

Learner: "Keep my enemies closer than my friends."

Teacher: "Ah, that's interesting. What - how do you do that? How would you keep your enemies closer than your friends?" and 
Learner: "A life lesson I learnt about was $<$ ???> a friend $<$ ??? $>$. She was constantly running away from home; not going to school and then $<$ ??? $>$ and giving her parents a hard time. In May I buried my friend."

Teacher: "Wow, there's a lot of pathos there. Ah, thank you."

Social relations are also strengthened at numerous points as a regulation strategy. For example, at the end of an intensive interaction establishing the evidence in the text for the bullying of the protagonist, some learners talk while the teacher is talking. The teacher responds with sarcasm:

"Gosh, this is an interesting development from someone who said 'I don't understand this poem.' Now please [her emphasis] share your thoughts with us, please!" [Learners laugh]. A culpable learner responds with: "I praise Nosipho and her group!" [Louder laughter] The teacher permits this, simply riposting: "She's not happy with that - she'd like individual credit."

Later, at the end of an intensive exchange where the teacher struggled to get learners to see "knowledge which was bitterer than. .." as identifying an emotion, a similar emphasis of social relations occurs. The teacher has asked:

"When you lose your father, Savannah, what, what should you be thinking about? Or at least, what does the speaker feel he should be thinking about?"

An unsolicited learner declares: "Freedom!" to which the teacher responds with wry acknowledgment: "Right, that was very unexpected." She quietly 'defuses' the potential escalation of learner affect by strengthening social relations without specifically validating the individual.

There are not many instances of emphasising social relations in the process of engagement with the poem itself. The clearest example occurs when the teacher directs attention to the second stanza and slightly widens inferential possibility:

“. . . he says 'I was a month past ten when I learnt about this.' Now I think the age is, is quite important - he's only just ten-years-old. Bearing that in mind, would you agree with the speaker that he is being selfish? Would you judge him for not thinking about his father?" 
Here social relations are strengthened as she elicits learners' personal opinions on this point, fostering an interpretive gaze involving extrapolation from a piece of text, and using real life knowledge of children, along with personal values about acceptable/unacceptable behaviour for bereaved tenyear-olds. Responding to numerous learners' answers of 'no' the teacher validates answers via her own qualified, interpretive elaborations:

“Alright, so maybe when you're young you actually, probably - it's probably a very natural sort of reaction" and

"Absolutely. And perhaps that to him is a more immediate reality than his father's death. He's got to go to school every day and get beaten up by someone."

A Specialisation analysis illuminates the interplay between the epistemic relations and social relations in a cultural heritage orientation, unravelling the emphasis on textual meanings in themselves. Attention to the play of both epistemic relations and social relations reveals the teacher's focus upon precision textual decoding as the base for literary interpretation, along with selective strengthening of social relations in order to increasingly orient learners towards literary, rather than personal, interpretations of the text, while offering them fairly detached forms of support in their struggles along this path.

\section{Tracing semantic profiles}

Utilising the concepts of semantic gravity (SG) and semantic density (SD) in relation to pedagogic practice helps reveal the movements, through time, between particularities and generalities; and denser, more conceptually integrated knowledge and more discrete, segmented forms of knowledge. Semantic gravity tracks the degrees of contextual specificity versus contextual independence of knowledge practices. Stronger semantic gravity $\left(\mathrm{SG}^{+}\right)$refers to knowledge closely tied to its originating contex,t while weaker semantic gravity (SG-) refers to knowledge operating across many specific contexts. Semantic density focuses upon degrees of concentration and distillation of knowledge, with stronger semantic density ( $\mathrm{SD}+$ ) referring to greater condensation of knowledge. Where strengths of semantic gravity and semantic density are inversely related to each other, this can be represented as a semantic wave. The diagram below shows three hypothetical semantic profiles: 


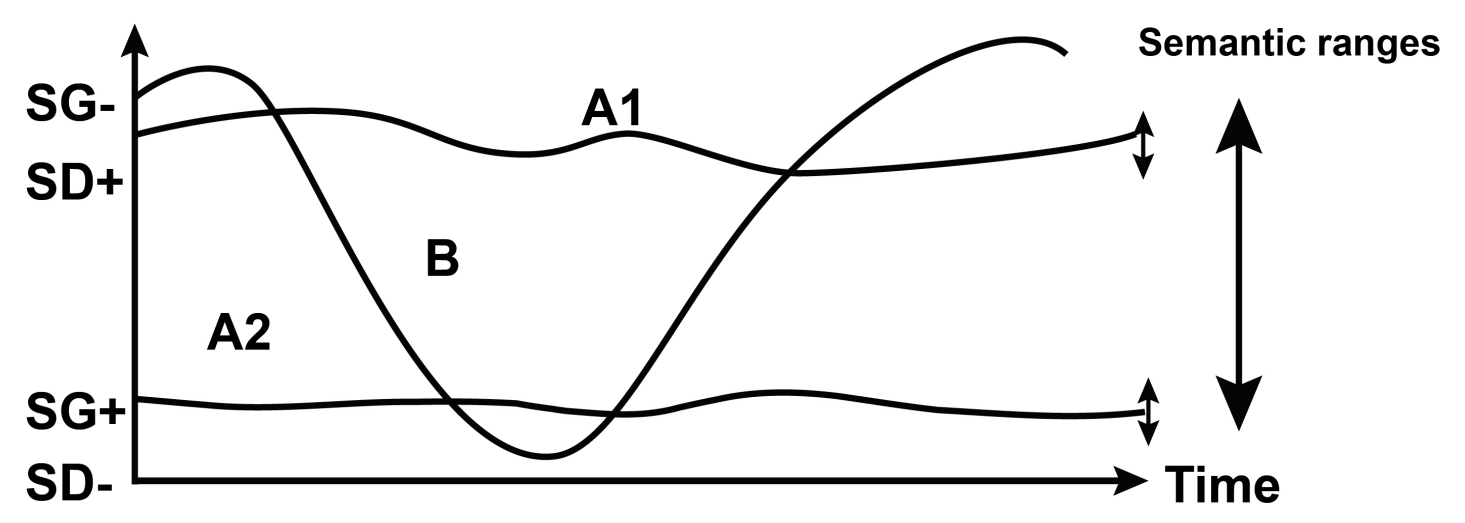

Figure 2: Three semantic profiles (adapted from Maton, 2014, p.143)

For this lesson, the broad semantic profile is represented below in Figure 3:

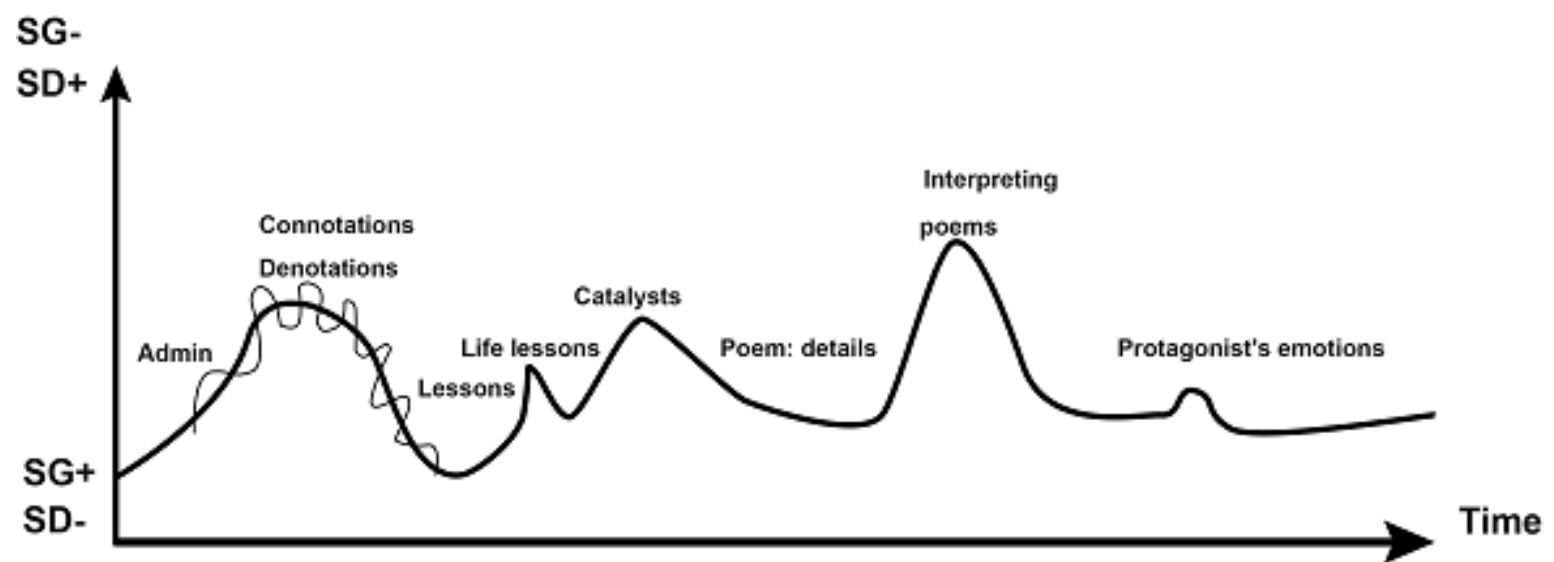

Figure 3:

Semantic profile: The Lesson

This profile represents a 'smoothing out' of many small variations in semantic gravity and semantic density. Particularly in Phase 4 of the class, represented in Figure 3 between the 'Connotations/Denotations' and 'Catalysts' peaks, many small shifts in semantic gravity/semantic density occur, generating semantic 'ripples', or 'fractal' waves (Maton, 2013, p.17) within the major wave movement. This is partially represented by the lighter line in Figure 5 above. Two examples of this semantic rippling are explored below.

Initiating phase three of the lesson Mrs Aldridge asks learners to recall a discussion on denotative and connotative meaning from an earlier language lesson. Semantic gravity is weakened and semantic density strengthened 
( $\downarrow \mathrm{SG} \uparrow \mathrm{SD}$ ) in her move from providing particular task information to invoking the conceptual categories to be used - abstract terms from the disciplinary field of language studies (semantics). She then strengthens semantic gravity through provision of the specific task focus and procedural directions:

"So I want you to start off by giving you one word, the word is 'lesson'. [She writes 'lesson' on the board and circles it.]"

She provides precise, locational direction, along with an implicit reason, in telling learners how they will be working diagrammatically with the word. These details strengthen semantic gravity, which is then weakened as the teacher shifts back to conceptual orientation: "But shall we start with denotation first?"

As the class moves into definitional revision of the terms, and their application to the concept of 'lesson', semantic gravity is strengthened through the provision of definitions. In response to the teacher's request for denotative definitions a learner offers: "a lesson that you learn through experience". The teacher's response, as is often the case in subsequent follow up moves, weakens semantic gravity slightly, via slightly more general rephrasing:

"ok, so something [my emphasis] that is learned through experience.

Similarly, after having requested and received a definition of 'connotation': "It's your own opinion", the teacher offers qualified acceptance and proceeds to unpack the idea more grammatically congruently, thus strengthening semantic gravity and weakening semantic density:

"what you think of when you hear that word".

She then immediately weakens semantic gravity a little by adding:

"the associations that word has for you",

by means of the nominalisation 'associations'. She reinforces this, and elaborates slightly as she then provides specific task instructions for the learners: 
"I'd like you to come up with perhaps about three or four connotations radiating out from the word lesson. Three or four connotations or personal associations that that word has for you."

Mrs Aldridge, in conjunction with the learners, has thus effected small shifts resulting in the unpacking and repacking of the concepts, from more to less abstract. These differing levels can be schematised as:

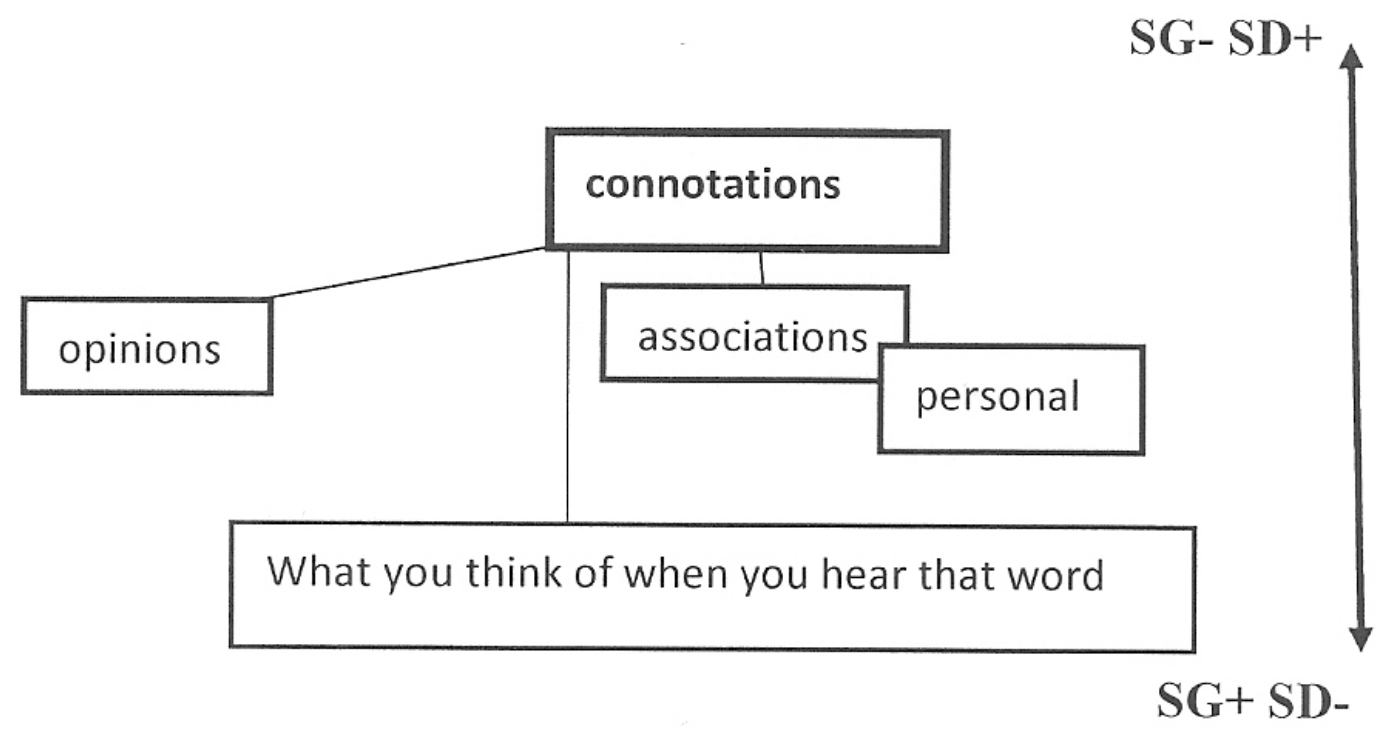

Figure 4: 'Connotations': Ideational Network

Potentially these variations contribute to learners building an ideational network around the concept, and alternative linguistic realisations of its meaning, thus increasing the semantic density of 'connotations' for them.

A further key semantic ripple unfolds as the teacher nudges her learners out of the everyday and towards a literary gaze of insights for life lessons. Semantic gravity is strengthened and semantic density weakened as learners brainstorm, and share personal lessons. Semantic gravity weakens, and semantic density strengthens slightly as the teacher generalises that all the life lessons result from some form of catalyst. The semantic rippling arises from the way the teacher handles learner responses: sometimes she defines terms, triggering a downward ripple; sometimes she nominalises verbs, producing a slight upward ripple. Overall, these semantic ripples generate slightly strengthened semantic density of 'school lesson' and 'life lesson'. She steadily reinforces her key focus - 'life lesson' versus 'school lesson', thus indexing for learners the need to transcend the immediacy of their experiences with school lessons, to more distant and abstract conceptualisations, ultimately weakening semantic gravity. 
A significant portion of the section of class identified on the semantic profile as 'Poem: details' entails small group discussion by the learners. The teacher moved between groups, scaffolding learners into fuller ranges of interpretation and capacity to 'wave' semantically themselves. As she moves the class into plenary, she weakens semantic gravity by summarising the processes just undertaken and thus discursively framing what has been, and will be done:

“... so essentially this poem is open to interpretation. And it's quite a difficult process, I think, to interpret a poem. You've got to keep asking yourself questions and once you arrive at one answer that generates the next question. So it's quite a complicated process."

By generalising beyond engagement just with this poem, she has weakened semantic gravity, explicating her understanding that poetry interpretation is a recursive process, requiring a gaze of perpetual inquiry. While there are many more instances of shifts in semantic gravity and semantic density worthy of close attention, space does not permit their exploration here.

\section{Concluding discussion}

Applying the LCT dimensions of Specialisation and Semantics to the analysis of this lesson's pedagogy enables nuanced illumination of aspects of its underlying structures and processes. These can be schematised in forms enabling comparision with other lessons, within English and in comparison with other disciplines. (A preliminary schematic overview synthesising both Specialisation and Semantic analysis of Phase 4 of the lesson is provided in Appendix One).

While it is clear the focus of this lesson is the development of the learner's literary gaze, and thus oriented more towards stronger social relations, the analysis reveals complex changes in the strengths of the epistemic relations and social relations. Epistemic relations are strengthened when the poem is approached as a textual source of information to be accurately identified and displayed. Social relations become more strongly emphasised when the 'meaning' of the text is used as a stimulus point to the retrieval and sharing of learner experiences and interpretations. A key pedagogic strategy of the teacher was to strengthen social relations to activate selective frames of 
reference in the learners, as springboard to the poem's meaning, rather than using the poem as a prism to refract and explore related learner experiences.

The focus on Semantics clarifies how the teacher moves from the specificities of learner experiences towards the presentation and modelling of potential components of her desired literary gaze. While the lesson begins, and broadly remains at a fairly strong level of semantic gravity, interleaved within this are 'semantic ripples', and some small semantic waves, falling within a fairly narrow range. Semantic gravity typically weakens around the introduction of abstract, nominalised terms then strengthens through learner contributions and weakens or strengthens slightly with the teacher's processes of elaboration, exemplification and reformulation. These potentially offer learners multiple routes into the meanings of words, and the construction of ideational networks of related concepts. The extent and nature of learner uptake of these opportunities is an issue for future research.

Overall the teacher's approach moves learners from an individualised, personalised sharing of their own experiences towards more abstracted personal experiences and finally, increasingly specialised processes of poetry analysis. Conceptually she builds a systematic, structured sequence, beginning with learners' prior knowledge. Along the way she (mostly implicitly) indexes for learners partial components of a poetic literary gaze. At various points she flags behavioural and discursive relations that help create and sustain the pedagogic coherence of the lesson and offer potentially transferable insights to learners on how to 'do' poetic analysis.

Behaviourally she indexes the need for learners to be active note makers, listeners and apprentice-partners co-constructing understanding of the poem with her. Cognitively she makes extensive use of interactive questioning chains - pushing learners towards higher levels of interpretive focus and understanding by rendering the more abstract inferential leaps she requires more concrete through her downward semantic waving.

Both overtly and implicitly, the teacher flags key discursive relations for the learners, articulating her sense of what is needed for poetry analysis.

Reinforcement of these is also often provided through her strong validation of learner responses clearly displaying such features of the desired literary gaze. These include: 
(a) articulating intra-textual relationships as the interpretive base; and

(b) dominantly focusing on the literary text as a self-contained 'bubble', with minimal projection of external experiences onto the text.

An LCT analysis illuminates her construction of poetry analysis as a probing, logical, reasoning process of interpretive inquiry, cultivating an epistemically oriented, relatively detached, cognitively associative literary gaze. It does so by means of a meta-language that potentially facilitates fruitful comparisons with other analyses of pedagogic practice, both within the field of school English (e.g. Christie and Macken-Horarik, 2007), and across other disciplines. Such analysis offers teachers sharper insight into the nature of their pedagogy and how it is placed in relation to the range of models of subject English available. This awareness may help teachers widen their pedagogic repertoires, feeding into more conscious decisions as to which models of English literary instruction may be most productively drawn on for particular pedagogic purposes to best meet the needs of specific learners (Macken-Horarik, 2014).

Further research is suggested to build an increasingly refined picture of variations in the forms of specialisation and semantic coding within the practice of individual English teachers, and between teachers in varying pedagogic contexts, across different aspects of the subject, and through time. Comparisons of variations in forms of specialisation and semantic coding with other home language subjects taught in South Africa would also be instructive in identifying how different communities of learners are being inducted into key literacy practices.

\section{Acknowledgments}

The National Research Foundation of South Africa for a grant that assisted in the final revision stages of this paper. 


\section{References}

Bernstein, B. 1996. Pedagogy, symbolic control and identity: theory, research, critique. London: Taylor and Francis.

Carminati, N. 2007. Investigating relationships between English Home Language curriculum documents and classroom practice. Unpublished MA dissertation. South Africa: University of the Witwatersrand.

Christie, F. and Macken-Horarik, M. 2007. Building verticality in subject English. In Christie, F. and Martin, J.R. (Eds), Language, knowledge and pedagogy functional linguistic and sociological perspectives. New York: Continuum, pp.156-185.

Clark, U. 2005. Bernstein's theory of pedagogic discourse: linguistics, educational policy and practice in the UK English/literacy classroom. English Teaching: Practice and Critique, 4(3): pp.32-47.

$\leq$ http://education.waikato.ac.nz/research/files/etpc/2005v4n3art2.pdf $>$ Accessed 15 July 2014.

Dyer, D. 2007. Why won't they learn? A contrastive study of literature teaching in two Cape Town high school classrooms. Unpublished MEd. dissertation. South Africa: University of Cape Town.

Ellis, V. 2009. Subject knowledge and teacher education. New York: Continuum.

Ensor, P. and Hoadley, U.K. 2004. Developing languages of description to research pedagogy. Journal of Education, 32: pp.81-104.

Gibbons, 2009. Lessons from the past? English Teaching: Practice and Critique, 8(1): pp.64-75.

$\leq$ http://education.waikato.ac.nz/research/files/etpc/files/2009v8n1 art4.pdf $>$ Accessed 18 July 2014.>

Green, B. 2008. English in the Antipodes: an editorial introduction. Changing English, 15(3): pp.255-258.

Harley, K. 1991. The emergence of 'English' as a school subject in Natal. The English Academy Review, 8: pp.1-14. 
Kantor, K.J. 2001. The English curriculum and the structure of disciplines. Theory Into Practice, XXII (3): pp.174-181.

Larsen-Freeman, D. and Freeman, D. 2008. Language moves: the place of 'foreign' languages in classroom teaching and learning. Review of Research In Education, 32(1): pp.147-186.

Macken-Horarik, M. 2013. English in a tempest: the value of metaphor and re-imagining grammar in English. English in Australia, 48(3): pp.46-54.

Macken-Horarik, M. 2014. Making productive use of four models of school English: a case study revisited. English in Australia, 49(3): pp.7-19.

Marshall, B. 2000. English teachers - the unofficial guide: researching the philosophies of English teachers. London: New York.

Marshall, B. 2003. The write kind of knowledge in English. English Teaching: Practice and Critique, 2(3): pp.83-94.

Maton, K. 2013. Making semantic waves: a key to cumulative knowledge building. Linguistics and Education, 24(1): pp.8-22.

Maton, K. 2014. Knowledge and knowers towards a realist sociology of education. London: Routledge.

Matruglio, E., Maton, K. and Martin, J.R. 2013. Time travel: the role of temporality in enabling semantic waves in secondary school teaching. Linguistics and Education, 24(1): pp.38-49.

Morrell, E. 2005. Critical English education. English Education, 37(4): pp.312-321.

Pike, M.A. 2003. On being in English teaching: a time for Heidegger? Changing English, 10(1): pp.91-99.

Slonimsky, L. and Brodie, K. 2006. Teacher learning: development in and with social context. South African Review of Education,12(1): pp.45-62. 
Sperling, M. and DiPardo, A. 2008. English education research and classroom practice: new directions for new times. Review of Research in Education, 32(1): pp.62-108.

Weideman, A., Tesfamariam, H. and Shaalukeni, L. 2003. Resistance to change in language teaching: some African case studies. South African Linguistics and Applied Language Studies, 21(1+2): pp.67-76.

Wright, L. 2002. Language as a 'resource' in South Africa: the economic life of language in a globalising society. English Academy Review, 19: pp.2-19.

Xinmin, Z. and Adamson, B. 2003. The pedagogy of a secondary school teacher of English in the People's Republic of China: challenging the stereotypes. Regional Language Centre Journal, 34(3): pp.323-337. 


\section{Appendix One}

Task Orientation - Brainstorming Exercise

(a) Language fusion - revising denotation and connotation

Individual learner (L) brainstorming exercise - 'Lesson'

[Linking statement - prior lesson]

SG- [Transfer - Language focus]

$\mathrm{SG}^{+}$[Narrowing - Task focus: Topic]

SG- [Content]

Procedural directions - locational, rationale (implicit)]

[Revising concepts]

$\mathrm{ER}+$

[Collaborative production - definitions]

SG- [Partial Teacher (T) validation][T generalizing]

[Procedural instruction: signals importance]

$\mathrm{SG}+\quad[\mathrm{L}$ answer $]$

SG+ [Qualified acceptance + elaboration - Grammatically congruent unpacking]

SG- [More abstract repacking]

[Varied redundancy - multiple processing routes.

Building ideational network]

$\mathrm{SG}^{+} \quad$ [Specific procedural instructions + time limit $] \quad \mathrm{SR}+$

(b) Plenary - sharing connotations of 'Lesson'

$\mathrm{SG}^{+}$[Validation of Ls' experiences]

$\mathrm{SR}++$

[Explication: personal gaze]

[Summarizes L contributions]

SG- [Redirects L focus]

SG+- [Expansion of answers:

SG+ Defines term; explains concept - link: Lesson focus

SG- Reformulation of answer - abstraction

SG- Amplification - expansion- cause-effect]

SG- [Flags wider issues]

$\mathrm{SG}+$ [Procedural instructions -task]

SG- [Topic abstraction + attributes]

SG- [Validation + abstraction: L responses]

[Narrowing of topic focus]

[Process comment; 'we' shift]

$\mathrm{SR}+$

[Indexing frame] 
Fiona Jackson

School of Arts

University of KwaZulu-Natal

fjackson@ukzn.ac.za 
